\title{
The Effect of Cross-cultural Background Knowledge Instruction on Iranian EFL Learners' Reading Comprehension Ability
}

\author{
Farhad Ghorbandordinejad \\ TEFL Department, Shahid Rajaee Teacher Training University of Tehran, Iran \\ Zahra Bayat (Corresponding Author) \\ Shahid Rajaee Teacher Training University of Tehran, Iran
}

\begin{abstract}
The present study investigated the effect of cross-cultural background knowledge on Iranian EFL learners' reading comprehension ability. To do this, sixty female EFL learners between 17 and 19 years of age were selected at a private language institute in Sabzevar based on their scores in language proficiency test and were randomly assigned to two groups of thirty. In order to determine homogeneity of students, a Nelson test was administered to the groups before any treatment. The teacher presented ten reading passages with the cultural content in both control and experimental groups. During the experiment, the teacher made her students familiar with target culture. On the other hand, the students in Control group did not enjoy any of the advantages of cultural warm-up activities which were designed to activate the cross-cultural background knowledge of students in Experimental group. At the end of this treatment, the two groups took a post-test to see whether the treatment had any influence on their reading comprehension ability. The post-test was piloted already. The results of the post-test showed that the groups performed differently on the post-test, which indicated that familiarity with specific culturally-oriented language reading text would improve Iranian EFL learners' reading comprehension ability.
\end{abstract}

Index Terms - schema theory, culture, cross-cultural background knowledge, reading comprehension, EFL learners

\section{INTRODUCTION}

Culture as the shared schemas of behaviors, creates the lives of mankind in a society. Culture and language are from the beginning conjoined to each other and language is not an absolute factor. Language is used in contexts of communication; it is bound up with culture in complex and multiple ways. Here, an obvious point is that culture is a very basic origin in language learning process.

Richards and Reynadaya (2002), Carrell (1988), and Stoller (2001) claimed that there are two reasons for considering reading as the most important skill in language learning. "First, most foreign language students often have reading as one of their most important goals." "Second, different pedagogical processes served by written texts help reading to receive this special focus."

Among English skills, reading is not the process of passive detecting and reading literally any more. Even it is the process of active decoding and confirming and also it is interplay between readers and the reading contexts. Hence, the ability to read and understand various passages has been identified as necessity to English proficiency.

According to Chen (2008), a considerable percentage of English language learners receive low ratings and they mark below their native-speaking counterparts on standardized reading comprehension tests. Littlemore (2003) state that the way in which students are able to use clues in the theme to interpret the context is affected by their cultural background knowledge. Students are probably more attend to clues that adapt to their cultural expectations than the ones that do not. In addition, Ruthemsley (2011) reminded us that cultural knowledge helps readers to reconstruct the text directing to more personally and culturally relevant prints. Having certain cultural context that is incorporated in the written language, the learners use information reserved in the memory not only to remember and think, but also to interpret and comprehend meaning.

The significance of cultural background knowledge in reading is essential to the schema theory. This theory deals with processing schemata by every reader. The schemata are cognitive constructs to organize the information in the long-term memory and these structures are sometimes culture-specific. Much understanding is provided by the readers' cultural background.

Bartlett (1932) stated that the role of background knowledge in language comprehension has been formalized as schema theory which has as one of its fundamental tenets. According to schema theory, a passage only provides directions for readers as to how they should retrieve or construct meaning from their own, previously acquired 
knowledge. This sort of knowledge is named the readers' background knowledge and the previously acquired knowledge structures are named schemata (as cited in Ghazanfari and Froughi, 2010).

Recent studies indicate that without enough background familiarity with L2 cultural knowledge, the readers can not realize the deep meaning of texts. There is, therefore, a requirement for research to investigate some invisible problems that prevent EFL students from learning to read in their second language.

This study examined the effect of cross-cultural background knowledge instruction on reading comprehension ability of low-intermediate native Persian-speaking English language learners.

Due to Nguyen (2011), there are two types of schemata: formal and context. Content schemata deal with general background knowledge related to the topic such as might be associated with the topic of an earthquake. Formal schemata deal with the rhetorical structure of language and a person's knowledge of the structure of a particular genre, such as news reports or journal articles. Carrell (1988) state that some vivid reading problems may be matters of insufficient background knowledge.

One of the most important findings of schema theoretic studies, exclusively in L2 reading, is the significant role of cultural background knowledge or cultural schemata plays in reading. With regard to the importance of cultural prior knowledge in comprehending the texts in this study, the problem is if Iranian EFL learners' cultural background knowledge affects on their reading comprehension performance.

According to Kluckhohn and Strodtbeck's (1961) Values Orientation Theory, all human societies have to answer a limited number of universal problems, that the value-based solutions are limited in number and universally known, but that different cultures have different distinctions among them. They proposed that the solution for the common problems preferred by a specified society reflects that society's values.

Reading as the level of conceiving of a text needs cultural background specific to the sort of texts for students to realize. The understanding of English texts depends on the access of cultural schema on that specific content of the text. Comprehension will fail, if the passages are not familiar to the students.

With respect to the findings, the cultural background of the reader will modify the type of information recalled. Hudson (2007) believed that through the process of interplaying with a text, the reader's mind searched folders that include some corresponding data with the intent and help to make comprehension. Schema theory demonstrates the process by which readers incorporate their own background knowledge with the data in a passage to find out that passage.

Recent studies, as well as teachers' experiences, have shown that NNS students in colleges and universities do not always follow the norms of politeness and appropriateness commonly accepted in their L2 communities despite having lived in those countries for several years. Similarly, in the academic studies, L2 learners may experience difficulties because they do not always understand what is expected of them and do not have access to the necessary socio cultural concepts that are ubiquitously manifested in the academy (Celce-Murica, 2001, p.445).

It is believed that because EFL/ESL textbooks represent a limited and controlled range of ideas, vocabulary items, and culturally-dependent concepts in Iran, they may not be the best means of explaining how the second culture affects language use. However, even within the limited thematic and lexical scope of textbook readings, learners may encounter comprehension difficulties that have to do with culture, since cultural inferences often need to be made to understand text.

The previous studies indicated the passive influences of background knowledge and the approaches for foreign language comprehension. Readers require comprehending what the text wants to say. They need to discover the context and make the unclear connections to make sense of the passage (Chen, 2008).

There is a need for study on the impacts of cultural and linguistic differences in basic science on the reading comprehension of adolescent L2 learners because of the late growth in the population of EFL students in the lowintermediate grades. This study is incorporated in the survey on language issues and culture. It can also profit EFL teachers and can be relevant to language policy makers to clarify the relationship between culture and language and to focus on schema theory. Rajabi (2009) believed that EFL learners should apply comprehension styles to reconstruct the writer's message.

According to Celce-Murica (2001), culture teaching in L2 reading goes far beyond instruction in vocabulary, idioms, and collocations, all of which are essential for understanding the meaning of the text. Context- and culture-specific connotations and implications of word and phrase meanings also need to be addressed. More urgently, however, socio cultural meanings and values greatly affects a learner's ability to comprehend text and the context in which it is employed. In authentic texts, such as those excerpted from advance print media (i.e. news, magazines and literature), culture-specific references, allusions, metaphors, and symbolism play a prominent role. Most importantly, however, the teaching of culture and its impact on text comprehension needs to be addressed at all levels of proficiency in order to build learners' awareness of cultural implications and references, without which few texts can be understood (pp.452453).

\section{Research Question}

Based on the objectives of this study, the following research question was formulated:

- What is the effect of cross-cultural background knowledge instruction on EFL learners' reading comprehension ability? 


\section{REVIEW OF LITERATURE}

Reading is one of the most necessary skills for daily life. People usually read because they want to obtain information about a specific subject. From a technical point of view, reading comprehension is a dynamic mental activity in which the reader interacts with the passage to extract meaning. Contrary to earlier beliefs that reading is a passive skill, it is now considered a process in which the reader picks out available information and cross-cultural familiarity only enough to understand the meaning of the text. In a text, words are combined in such a way that their relative position and patterns contribute to their collective meaning (Farhady, 2005).

There are two main outlooks about reading. The first assumes that meaning exists in the text itself and it is the textbased factors that determine meaning; for the second view, meaning is the product of the readers interacting with the text and it is inside-the-head factors that determine meaning (Ghazanfari and Foroughi, 2010).

Considering information processing system, there is contrast between ways in which humans analyze and process language as a part of comprehension and learning. In top-down processing, the system makes use of higher level, non sensory information to predict or to interpret lower level information that is present in data. In the other way, bottom-up processing; the system makes use of the information present in the input to achieve higher level meaning.

Decoding model deals with holding the utterance in short-term memory, analyzing the utterance in to segments to identify phrases and other linguistic units and the underlying prepositions (Richards and Schmidt, 2002).

Anderson (1984) made a comparison between the two basic approaches to comprehension. Skills model states that reading is made of separate skills and has a hierarchical skills sequence. In this model, applying reading skills leads to meaning and reading is considered as a passive and precise process.

On the other hand, psycholinguistic model considers reading as an integrated process that has no one sequence of skills. Reading is meaning centered and an alternative language process and also an active process (as cited in Chastain, 2002).

Regarding reading strategies, the readers scan the text when they want to locate the specific piece of information without understanding the rest of the text. While through skimming, the readers read rapidly to get the main idea or ideas from a text.

Tierney and Pearson (1985) had some recommendations to teach reading. EFL teachers should be sure about students' prior knowledge of a topic or text genre before reading and encourage reading, provide their students to evaluate their own idea, help students to use reading strategies, help them to develop story maps (flow chart of key events or time line) before reading stories, encourage students to regard why and when the author is writing and develop a small discussion to accomplish the goals of reading. Krashen and Terrell (1983) focused on the reading strategies of read for meaning, not looking up every word, predicting meaning and using context (as cited in Chastain, 2002).

Richards and Schmidt (2002) defined "culture" as follows:

The set of practices, codes and values that mark a particular nation or group: the sum of a nation or group's most highly thought of works of literature, art, music, etc. A difference is sometimes made between "High" culture of literature and the arts, and small "c" culture of attitudes, values, beliefs, and everyday lifestyles. Culture and Language combine to form what is sometimes called "Discourses", i.e. ways of talking, thinking, and behaving that reflect one's social identity. The cultural dimension of language learning is an important dimension of historical, political, and artistic) regarded as necessary for informed participation in a nation or culture. Cultural literacy may or may not be something possessed by a person who is bilingual (pp.137-138).

According to Hill (2002), cross-cultural psychology has two large aims: to understand the differences between people who come from different cultural backgrounds and to understand the similarities between all the people. Kluckhohn and Strodtbeck's Values Orientation Theory suggests that all human societies must answer a restricted number of universal problems, that the value-based resolves are limited in number and universally known, but that various cultures have various distinctions among them. Mentioned questions include humans' relations with nature, time and each other, as well as basic human motives and the nature of human nature.

According to Xiaoqin (2005), Schemata are $\mathrm{n}$ significant construction in both social and cognitive psychology. The effects of schemata on memory, perception, consideration and interpretation are well documented. The schema theory designed by Bartlett stresses the significance of schema and background knowledge for text comprehension. In other words, schema theory states the role of background knowledge in language comprehension and illustrates how readers recapture or construct meaning from their own past experience pre-existing knowledge. Schemata state that knowledge stored in our mind is well-organized rather than randomly organized. They form independently by the contents each schema possesses. On the other hand they are related by nodes, which empower them to communicate when essential. Mostly all cognitive descriptions of schema stem from Bartlett as an active organization of past responses of past experiences, which must always be supposed to be function in any well-adapted organic reaction.

With respect to this theory, readers use a process of semantic construction to create meaning from a written passage, which itself has no meaning (Chastain, 2002).

Geert Hofstede's theory of cultural dimensions describes the impact of a society's culture on the values of its members, and how the values relate to behavior, using a mixture derived from factor analysis. The theory has been comprehensively used in several fields as a paradigm for research, particularly in international management, crosscultural psychology and cross-cultural relationship. Hofstede developed his primary model as a result of exploiting 
factor analysis to examine the results of a world-wide survey of employee values by IBM in the 1960s and 1970s. The notion was one of the first that could be quantified, and could be used to clarify observed differences between cultures. The original theory proposed four dimensions along which cultural values could be analyzed: individualism, collectivism; uncertainty avoidance, power distance (strength of social hierarchy) and masculinity-femininity (task orientation versus person-orientation) (Hofstede, 2013).

Nishida (1999) stated that the need of familiar knowledge people use when they enter a familiar situation in their own culture. He defined cultural schemas in social interactions as cognitive structures containing knowledge for face to face relationships in one's cultural environment. As cited in most resources, schemas are knowledge of past experiences which is organized in to relevant knowledge classes and used as guidance in familiar situations. Cultural schema theory explains that interacting with members of the same culture in specified situations many times or taking about some of information with them makes cultural schemas that are stored in the brain. With this occurrence, communication becomes much easier.

All people have to apply "global village" to describe the actual world. Because of frequent cross-cultural interaction, the world has become tinier and tinier. Hence, it seems that we live in the same village. However, it does not presently mean that differences of cross-culture become tinier and tinier. Likewise, it may be that there is a growth in misunderstanding and communicative barriers because of constant cross-cultural communication, as a foreign language student, we should not only acquire the knowledge of language, but also try our best to encounter the cultural and social aspects of English countries and learn the background of literature, geography, history, ceremonies and local condition. We should use every means to empower our field of thought. Just in this manner, we can get better finding out the differences between English culture and another one so as to efface the comprehension barriers of cross-culture communication and ameliorate our overall capabilities in English reading (Lin, 2013, p.8).

Tavakoli, Shirinbakhsh and Rezazadeh (2013) clarified the effect of cultural familiarity, that of nativization on deduction and literal understanding in reading comprehension. Additionally, the study considered the general attitude of Persian EFL students toward the nature of nativization in short stories. Generally, there is a punctual relationship between reading comprehension and nativization at both the literal levels and inference. Moreover, participants did not support nativization of culturally bound words in English short stories and the subjects stated their positive attitude toward studying the original English stories. Hosseini Asl and Kouhi (2013) surveyed the effect of awareness raising activities on the reading comprehension of culturally-bound materials. The results of the post-tests of two groups indicated that awareness raising activities facilitate reading comprehension of culturally-bound materials. In fact, the experimental group achieved considerable success in reading comprehension than control group.

Hill and Liu (2012) investigated the interaction impact of background knowledge and language proficiency on TOEFL iBT reading texts. No evidence of interaction between proficiency and background level was observed for the bundle-level analysis. As a whole, the TOEFL iBT reading texts were neither advantageous nor disadvantageous to those who had physical science backgrounds or were familiar with a determined culture, and this holds for both the higher and lower proficiency groups. This finding adds proof in support of the validity of the TOEFL iBT, in that the scores on theses texts containing cultural information and subject content were not biased against any knowledge group. The results provide record that it is possible for the TOEFL iBT to create reading texts that are contextualized in cultural material and subject but at the same time free from bias at the text level.

Their findings in the study also advanced our understanding of the impact of background knowledge in reading comprehension.

Nguen (2012) exploited a quantitative method to explore the dynamic effects of schemata (background knowledge) and time constraint on the reading comprehension of Vietnamese ESL students. As explained by him, background knowledge is a significant factor in reading comprehension which had been found to play controversial roles.

According to Bilgileri (2012), cultural nativization of the content and factors relevant to background knowledge in the nativized passage had a facilitative impact on comprehension of the short texts and on inferring the meaning of the unknown vocabulary by the learners. Those learners who received the nativized version of the passage got higher scores both in vocabulary tests and reading comprehension compared to the learners who received the authenticated version of the text.

The central theme of another study by Gurkan (2012) was as the same as the others. In comparison, it also discovered if activities can make up for the lack of learners' related cultural schema. It has been shown that culturally bound background knowledge of the students plays a role in their comprehension of the passage. If a number of textual and contextual hints with which display cultural familiarity are provided, Turkish EFL students with a probably advanced degree of L2 proficiency can draw deeper and richer inferences from a short narration from the foreign language culture. Besides, the learners who read the original narration without or with reading activities marked lower than their peers who read the nativized issue did not have to deal with unfamiliar names and culturally distant contextual indexes, resulting in worse comprehension gains. (Gurkan, 2012, pp.33-34).

Dehghan and Sadighi (2011) investigated the effect of cultural background or cultural schema on the performance of Iranian EFL students on local (bottom-up) and global (top-down) processes. The findings showed that Iranian students in their study performed significantly better on local items compared with global items both for unfamiliar texts. It was also observed that their overall performance was mostly influenced by text familiarity. Their higher scores on local 
items can be explained by the fact that these items are totally easier to process due to the linguistic context available. In contrast, the difficulty of the global items can be explained because our EFL learners need extra linguistic knowledge to process such items. Also, this difference could be attributed to the teaching situation in which language teachers do not teach students how to read at all and learners are not familiar with higher-level, global processes being important in reading comprehension.

The study done by Rudemsley (2011) showed us that the cultural background of ESL student has an effect on comprehension of English texts. The findings had also illustrated that students who belonged to a various cultural environment exploited the written texts differently because the cultural quantity was not from their own background. It was also explained that pupils who did not possess the relevant schemata found it difficult to realize English written passages. It shows that cultural background facilitates comprehension of texts. It was mentioned that the schema theory that the unfamiliar theme of a text, weather cultural or topic-related, has an impact on reading comprehension. Students who use English as a L2 are more probably to have low reading comprehension capability owing to lack of background knowledge that may be necessary for certain passages (Rudemsley, 2011, p.63).

Ryan (2010) analyzed culturally bound background knowledge that both Japanese and Americans may use when they interact in a government or business context. Based on his findings, our culture-specific schemata are largely unrealized and often factious in cross-cultural contexts. Those in arranged international context will acquire to become more aware of the expectations they bring to the international workplace. Moreover, cultural schemata cause differences in reception and in turn, commentary of fundamental concepts that both Japanese and Americans on the surface seem to be in agreement on. The implications of these sorts of tacit misunderstandings could lead to larger, open disagreements and mutual distrust negatively affecting future interactions. In the past, cognitive experts have mainly used schema theory as a medium to survey reading and literacy studies.

In 2010, Pollap also illustrated that there is a positive relationship between English language students' knowledge of American culture and their level of English language proficiency. It could be stated that general culture knowledge should be complemented to the English language curriculum to help students with language learning. His study confirmed the similarity of general knowledge of the target culture in regard to EFL learning outcomes. American cultural knowledge forestalls the English proficiency of English language students. Cultural awareness affects L2 teaching since culture is a comprehensive composite with a large implication, and each element in it may be exhibited in vocabularies. Learning words while attending to culture is crucial and vital. Hence, an understanding of the cultural background of vocabularies helps students clarify the differences of usage and meaning of word in the target language. Having a detailed understanding of word helps students' reading, speaking, listening and writing skills development because selection of suitable vocabulary in essential for accurate interpretation. It is easier for language students to realize a conversation related to cultural conditions with which they are familiar. Additionally, language students may understand not only literal meanings but also deeper meanings eradicated in the speaker's culture. It is manifest that due to the higher ratio of native speakers of English, participants in the northeast had greater chance to absorb American culture while interplaying with American professors, friends, and American colleagues than subjects in the central area, so learners in the northeastern area gained a higher mark on American culture test than learners in the central area.

Ghazanfari and Foroughi (2010) investigated the effect of schema activation by exploring the effectiveness of two kinds of pre-reading strategies (schema theory-based pre-reading activities and text-based ones) on reading comprehension of Iranian intermediate EFL readers. The results illustrated that EFL learners who were instructed to apply pre-reading strategies outscored the learners who were taught without using certain pre-reading strategies. Also, the group who had applied a schema theory-based pre-reading strategy outscored the group who having applied a textbased pre-reading strategy.

Sharafi and Barati (2010) explored the effect of schemata activated by culturally familiar texts on test takerse performance on cloze tests. It also investigates whether there is any difference in the performance of males and females on culturally familiar cloze tests. While the results demonstrated that males and females did not perform significantly different on culturally familiar cloze tests, it was found that the performance of the participants on culturally familiar cloze tests was significantly better than their performance on culturally neutral cloze tests. The study, therefore, suggested that culturally familiar texts may help test takers show their true comprehension ability and in turn perform better on cloze tests.

According to Shaghasemi \& Heisey (2009), Iranians have more positive cross-cultural schemata of Americans than Americans do of Iranians in both range and degree.

Erten and Razi (2009) confirmed what has been widely acknowledged as the positive impact cultural familiarity and background knowledge on reading comprehension.

Chen (2008) also found that comprehension consists of interplay between reader-based and text-based information. It means that reading is interplay between a text and a reader. Reading is a two-way communication between the information printed and readers' minds. Through reading, the reader relates the new data to his/her background knowledge. He argued that fluent readers apply the smallest quantity of text information essential relating to his/her existing conceptual and linguistic schemata to understand a text. In short, reading is constructing and the comprehension of meaning. Readers construct meaning by interplaying with the passage, on the basis of their background knowledge about the world. There is a distinction between comprehension questions and reading questions. 
Some students may not have a reading problem, but he/she as a comprehension problem which prevents his/her from succession in reading. To become a nice reader, since it is not only the words of which one has to conceive the meaning. She also showed that a reader can guess accurately what the words mean in a special context simply because he/she knows what is being talked about. Students learn words faster in a familiar as compared to an unfamiliar context. Accordingly, without relevant precedent knowledge, students cannot guess unknown words correctly and readers use multiple knowledge sources in word recognition. One needs a treasure of relevant knowledge that is wider than the words of a text. Without wide knowledge, learners' reading comprehension will travail and their scores on reading comprehension texts will not improve. Through the past few decades, there was an increase in providing direct instruction strategies to help learners to consciously use the styles in various contexts. However, none of those ways attempt to build up students' knowledge.

Chen (2008) investigated the impacts of background knowledge and previewing texts on the reading comprehension of native Mandarin-speaking English language learners (ELLs). He applied previewing activities to provide the subjects with relevant background knowledge to help them figure out the texts. With respect to her findings, the previews and culturally familiar texts facilitate the process of ELL students' reading comprehension.

Chang (2007) surveyed the issue of cross-cultural background knowledge instruction and its influences on the reading comprehension. His study had shown a considerable relationship between EFL reading comprehension and background knowledge. Background knowledge was exactly beneficial in relating the contextual meanings to EFL readers' comprehension. With respect to the small sample, additional studies with larger sample should be steered in the future. Doe to the strengths of employing readers' background knowledge, several manners could be used to reading courses in EFL language contexts. With culturally relevant information, EFL learners' familiar previous experiences should be valuable to their reading comprehension.

Alpteken's (2006) findings demonstrated that the nativization of a short narration from L2 culture simplifies L2 students' inferential comprehension significantly and does not affect their literal understanding. The results reminded us that L1 inference skills are employed more constantly and efficiently in the L2 passage content and previous knowledge are homological. He believed that there should be the replication with participants who are less exposed to L2 and its culture. Because in his investigation the subjects were advanced EFL learners with a TOEFL score of 565 and also some of them had graduated from English-medium high schools in Turkey where they had been familiarized to a deal with the cultures of English conversing nations.

In 2004, Pulido did a research to investigate the influence of cultural familiarity and L2 text sight vocabulary on L2 tacit vocabulary gain during reading. Students at the high-intermediate level of proficiency illustrated greater word gain scores after reading about scenarios with which they were familiar, due to prior background knowledge and experience. It means after reading the culturally familiar versions of the stories learners showed better recall for having seen the target nonsense vocabularies than after reading culturally unfamiliar versions of the scenarios. This result provides additional support for schema-theoretic and knowledge-based views of recall and acquisition (Pulido, 2004, p.36).

Fuhong (2004) recommended us that schema theory has positively affected the teaching reading. Additionally pre reading activities-building up absent schemata and activating resident schemata- can ameliorate ESL/EFL reading comprehension in many situations. EFL teachers should take the time to verify the usefulness of the activities they use and attend to possible schema-interference or non-activation. Consistent adjustment is needed in accordance with the learners' language proficiency.

In 2002, a survey conducted among 400 Chinese middle-school students and tertiary EFL majors gave a justly clear picture of their perceptions of prior conceptual, linguistic and socio cultural knowledge in terms of respective contributions to reading comprehension. The information indicated two different tendencies for the two participating groups of subjects. The middle-school learners tended to give the top ranking to the choices concerning either the reader's linguistic knowledge or the linguistic characteristics of the passage; the tertiary EFL majors, however, were probably to give the top priority to the options that concern either the reader's prior conceptual and socio cultural knowledge or the socio cultural background and conceptual knowledge presumed by the passage (Lin, 2002).

According to his findings, in summary, the study indicated that middle-school students perceive the reader's previous linguistic knowledge as the most important element for EFL reading comprehension, while tertiary EFL majors consider the reader's previous socio cultural knowledge as the most important. The survey also showed that, as readers' previous linguistic knowledge increases, they tend to link less importance to it, especially the knowledge of formal structures and syntax. At the same time, conceptual and socio cultural knowledge assumes greater importance. The perceived significance of previous linguistic knowledge seems to start diminishing around the end of secondary education when the learners have acquired a vocabulary of 3000 words and the fundamental syntax and formal structures of English. The final replacement of linguistic knowledge by socio cultural knowledge as the top element affecting reading comprehension seems to take place about one year after onset tertiary EFL education. This may well be considered as an allusion of the EFL threshold level for EFL students in China.

Finally, the conclusions inferred from the study seem to provide additional assistance to the L2 Linguistic Threshold Hypothesis: that L2 reading comprehension is both a matter of reading and a matter of language. With onset L2 readers, reading comprehension is more an emphasis of language than an issue of reading. The findings of the study also cast sidelight on the matter of the relations between the knowledge of first language and second language. It looks that the 
exemplar in L2 reading comprehension education is not if L2 language instructors should tap into L2 learners' L1 reading capability and L1-related knowledge, but how to tap into it to preserve a maximization of the positive L1 transfer (Lin, 2002, p.187).

\section{Methodology}

\section{A. Participants}

The study had two separate groups of participants: 1) twenty pilot study's participants by whom the researcher could check the problematic parts of the post-test and 2) real study's participants.

This research was conducted at a private institute of Sabzevar. The participants of this research were female lowintermediate students and they are currently pre-university students studying English in this private institute. The participants of this study were sixty students. They were female students between 17 and 19 years of age. To account for group homogeneity, a Nelson proficiency test (Fowler and Coe, 1976) was administered to about 130 students from three different majors of math, science and literature, and 60 students that had the same level of proficiency were chosen, and the rest of them were discarded. The selected students were then randomly divided into two groups of 30 (experimental group and control group).

\section{B. Instruments}

\section{Language Proficiency Test}

In order to insure the homogeneity of the control and experimental group in terms of English language test, a Nelson test (Fowler and Coe, 1976) was administered to these groups. It consisted of three parts, cloze test, structure test and vocabulary. All parts were in the form of multiple choice questions. There were 50 items and the item allotted was 45 minutes.

\section{A reading comprehension test (post-test)}

The researcher constructed a reading comprehension test as the main post-test. Regarding participants' interest, the researcher prepared five short stories for low-intermediate level. The content of stories was exactly based on the cultural contents in ten passages. Each text was followed by six multiple choice questions. As a whole, the test included 30 questions and cultural contents regarded for this study. This test was piloted in Sabzevar Marefat Institute.

According Eghtesadi (2005), the level of difficulty of a text should be appropriate for the readers. Different ways determine suitable reading texts. The core of these formulas is the belief that the more polysyllabic words in a sentence, the more difficult it is and the less sentence in a paragraph, the more difficult the paragraph will be. One of these formulas is The Gunning Fog Index (Robert Gunning, 1952). The researcher calculated the readability of each text (short story) prepared for post-test. Regarding the results, the texts had indexes below 12 which were suitable for lowintermediate level in this study.

\section{Procedure}

\section{Pilot Study}

For post-test, the researcher made a reading comprehension test with the cultural contents including in those ten reading passages and with 30 multiple choice questions. The items of the post-test were piloted with 20 students who have similar educational backgrounds with the real participants in the study.

The study revealed that each item performed satisfactorily, suggesting that the post-test had high Cronbach's alpha (r $=.869$ and $\mathrm{p}<.01$ ), which was considered to be consistent enough to go on conducting the post-test to the real sample. To validate the test, five TEFL professors reviewed the test and solved the problems.

\section{Main Study}

The purpose of this research was to investigate the effect of cross-cultural background knowledge instruction on Reading Comprehension ability of Iranian EFL learners. The researcher administered the process of the whole study by herself.

Data were collected during the second semester of the academic year. The researcher submitted a completed research request application and a detailed proposal package to the private institute's Department of Research, Planning. The research committee under the direction of the department of research and planning has specific guidelines set to standardize research activities effectively without the district, in order to protect individual right of participants in the system and to avoid all interference with the laws. In this study the researcher applied Treatment Lessons by herself.

The researcher administered a sample of Nelson Proficiency Test to select homogeneous groups. Respectivly, she chose the persons scored with the range of one standard deviation above and below the mean as the main participants of the study. With respect to homogenaity, 60 students out of 130 were chosen for the main study.

This experiment was conducted over a two-month period. All the tests and treatment sessions were conducted during Low-intermediate course for three hours per week. Planning for the study was as follows:

Week 0: Administering Proficiency Test/ Week 1: Treatment Lesson (Lesson Plan for Treatment Sessions 1/Week 2: Treatment Lesson (Lesson Plan for Treatment Sessions 2 \& 3) /Week 3: Treatment Lesson (Lesson Plan for Treatment Sessions 4 \& 5) /Week 4: Treatment Lesson (Lesson Plan for Treatment Sessions 6 \& 7)/ Week 5: Treatment Lesson (Lesson Plan for Treatment Sessions 8 \& 9)/ Week 6: (Lesson Plan for Treatment Session 10)/ Week 7: Post-test. 
Homogeneous students were randomly put in two groups (Experimental group and Control group). Each group contained 30 low-intermediate students. The real treatment was applied from the beginning of the first week (week1) only in Experimental group. The participants cooperated in Treatment Class for two days per week. Ten lesson plans were conducted for 10 sessions.

The reasearcher, who applied the traetment by herself, presented selected readign passages with pre-reading knowledge cultural warm-up activities and some later culture-bound quesions in experimental group. Fr example: If the cultural content of a reading passage was Christmas, she provides her students with background knowledge of Christmad customs and western beliefs in this regard.

There were 30 low-intermediate students in the Control group. The students in Control group did not enjoy any of the advantages of cultural warm-up activities which were designed to activate the cross-cultural background knowledge instruction of students in Experimental group. The students in Control group were provided with no pre-reading activities and the teacher (the researcher) was supposed to answer the students' important questions.

Prior to the main post-test, a pilot study was conducted using twenty low-intermediate EFL learners from Sabzevar Marefat Institute. The students involved in the pilot study did not participate in the main study and they are characteristically similar to the main participants. The pilot test was deemed important for identifying any problems and omissions as well as checking time spent in responding. Following the analysis of the pilot study data, ambiguous or unclear items were either rephrased or removed.

In the last week, and after ten Treatment Sessions, the post-test was administered in the last week. Both groups had the post-test at the same time. One Reading Comprehension Test with the content of previous cultural knowledge was used for the post-test and the students had to answer 40 multiple questions.

\section{RESULTS AND DISCUSSION}

A one-way ANOVA was applied to show whether there was a significant difference between these three groups. In other words, obtained scores were then submitted to a one-way ANOVA to determine whether the mean differences were statistically significant (Table 4.1).

TABLE 4.1

TEST OF HOMOGENEITY OF VARIANCES

\begin{tabular}{|l|l|l|l|}
\hline \multicolumn{3}{|l|}{ Nelson } & df2 \\
\hline Levene Statistic & df1 & Sig. \\
\hline 786 & 2 & 127 & .458 \\
\hline
\end{tabular}

As the table shows, the Sig value is 0.458 and greater than 0.05 . Hence, the results show that these three groups were homogenous as far as language proficiency in concerned.

The means for each class are given in Table 4.2. In this Descriptive Statistics table, the mean for the math students is 18.3. The mean for the science students is 19.4 and the mean for literature students is 18.8. The standard deviation math students is 9 (when rounded), the standard deviation for science students is 7.3 and the standard deviation for literature students is 7.8. The number of participants in each group $(\mathrm{N})$ is 20 . The means for each group are given in Table 4.3. As outlined in the table, there is a significance difference in reading scores for control group $(\mathrm{M}=12.9, \mathrm{SD}=6.7)$ and experimental group $(\mathrm{M}=24.7, \mathrm{SD}=3.4)$.

TABLE 4.2

DESCRIPTIVE FINDINGS FOR THREE CLASSES

\begin{tabular}{|c|c|c|c|c|c|c|c|c|}
\hline & \multirow[b]{2}{*}{$\mathrm{N}$} & \multirow[b]{2}{*}{ Mean } & \multirow[b]{2}{*}{ Std. Deviation } & \multirow[b]{2}{*}{ Std. Error } & \multicolumn{2}{|c|}{$95 \%$ Confidence Interval for Mean } & \multirow[b]{2}{*}{ Minimum } & \multirow[b]{2}{*}{ Maximum } \\
\hline & & & & & Lower Bound & Upper Bound & & \\
\hline Class 1 & 20 & 18.3500 & 8.97526 & 2.00693 & 14.1494 & 22.5506 & 5.00 & 30.00 \\
\hline Class 2 & 20 & 19.4000 & 7.38704 & 1.65179 & 15.9428 & 22.8572 & 6.00 & 30.00 \\
\hline Class 3 & 20 & 18.8500 & 7.88920 & 1.76408 & 15.1577 & 22.5423 & 8.00 & 30.00 \\
\hline Total & 60 & 18.8667 & 7.98402 & 1.03073 & 16.8042 & 20.9292 & 5.00 & 30.00 \\
\hline
\end{tabular}

TABLE 4.3

DESCRIPTIVE FINDINGS FOR EXPERIMENTAL AND CONTROL GROUP

\begin{tabular}{|l|l|l|l|l|l|}
\hline & Group & $\mathrm{N}$ & Mean & Std. Deviation & Std. Error Mean \\
\hline Reading & control & 30 & 12.9667 & 6.77970 & 1.23780 \\
\cline { 2 - 6 } & experimental & 30 & 24.7667 & 3.42086 & .62456 \\
\hline
\end{tabular}

Prior to the main post-test, a pilot study was conducted using twenty low-intermediate EFL learners from Sabzevar Marefat Institute. With respect to Table 4.4, the alpha coefficient for the thirty items is .828 , suggesting that the items have relatively high internal consistency.

TABLE 4.4

RELIABILITY STATISTICS

\begin{tabular}{|l|l|l|}
\hline Cronbach's Alpha & Cronbach's Alpha Based on Standardized Items & N of Items \\
\hline .828 & .869 & 30 \\
\hline
\end{tabular}


- What is the effect of cross-cultural background knowledge instruction on Iranian EFL learners' reading comprehension ability?

As Table 4.5 shows the Sig value for Levene's Test is 0.015 and greater than 0.05 , hence we should read from the top row. The Sig. (2-Tailed) value in the first row is 0.00 . This value is less than 0.05 . Because of this, we can conclude that there is a statistically significant difference between the reading score in control and experimental groups. Since our Group Statistics box revealed that the Mean for experimental group is greater than the Mean for control group, we can conclude that participants in experimental group are got greater reading scores than participants in control group.

TABLE 4.5

INDEPENDENT SAMPLES TEST FOR CONTROL AND EXPERIMENTAL GROUPS

\begin{tabular}{|c|c|c|c|c|c|c|c|c|c|c|}
\hline & & \multicolumn{2}{|c|}{$\begin{array}{l}\text { Levene's Test for } \\
\text { Equality of Variances }\end{array}$} & \multicolumn{7}{|c|}{ t-test for Equality of Means } \\
\hline & & \multirow[t]{2}{*}{$\mathrm{F}$} & \multirow[t]{2}{*}{ Sig. } & \multirow[t]{2}{*}{$\mathrm{T}$} & \multirow[t]{2}{*}{ df } & \multirow{2}{*}{$\begin{array}{l}\text { Sig. } \\
(2 \text {-tailed })\end{array}$} & \multirow{2}{*}{$\begin{array}{l}\text { Mean } \\
\text { Difference }\end{array}$} & \multirow{2}{*}{$\begin{array}{l}\text { Std. Error } \\
\text { Difference }\end{array}$} & \multicolumn{2}{|c|}{$\begin{array}{l}95 \% \text { Confidence Interval of the } \\
\text { Difference }\end{array}$} \\
\hline & & & & & & & & & Lower & Upper \\
\hline \multirow{2}{*}{ Reading } & \begin{tabular}{|l|} 
Equal \\
variances assumes
\end{tabular} & 6.245 & .015 & -8.511 & 58 & .000 & -11.80000 & 1.38644 & -14.57527 & -9.02473 \\
\hline & $\begin{array}{l}\text { Equal variances not } \\
\text { assumes }\end{array}$ & & & -8.511 & 42.868 & .000 & -11.80000 & 1.38644 & -14.59628 & -9.00372 \\
\hline
\end{tabular}

\section{DISCUSSION AND CONCLUSION}

According to the results of this study, cross-cultural background knowledge instruction has a significant effect on reading ability of Iranian EFL learners. Cross-cultural background knowledge instruction about western holidays, wedding customs, ways of life and relationships would help readers more and more to realize the main ideas of English passages on these contents.

However, the principal limitations of this study are a small sample and female participants. Therefore, additional studies with a larger sample should be conducted in the future. Also, it will be needed a study on male EFL learners.

To conclude, cross-cultural background knowledge instruction has an important effect on reading ability among female EFL students in Iran. In another word, having a strong cross-cultural knowledge would improve reading comprehension ability. The results of the study are helpful in highlighting the fact that the nature of cross-cultural background knowledge instruction can have divergent effects and promote reading comprehension. For instance, cultural pre-reading activities have a facilitative role in giving the relevant background knowledge about the text if a mismatch occurs between readers`schemata and the writer`s, they also attempt to activate readers` schemata if they share similar background knowledge with the writer. Chastain (1988) states that pre-reading activities also motivate readers to read the text. While-reading activities permit readers to get the writer's message through a number of activities such as; skimming and specific information about the text through scanning (Brown 2001).thus they are thought to contribute to comprehension. Finally, with the use of post-reading activities readers clarify if any unclear interpretations occur while reading as a last step.

\section{REFERENCES}

[1] American folklore. (2012). I'm coming down now: An Albert Ghost Story. Retrieved June, 30, 2012, from www.americanfolklore.net/folklore/2011/02/im_coming_down_now.html.

[2] American Psychological Association. (2010). Publication manual of the American Psychological Association (6th ed). Washington, DC: Author.

[3] Alptekin, C. (2006). Cultural familiarity in inferential and literal comprehension in L2 reading. System, 34, 494-508.

[4] Bilgileri, M. (2012). The effect of background knowledge and cultural nativization on reading comprehension and vocabulary inference. Journal of Education and Instructional Studies in the World. 2 (4), 188-198.

[5] Brown, D. (1994). Teaching by Principles: An Interactive Approach to Language Pedagogy. New Jersey: Prentice Hall Regents.

[6] Carrell, P. L. (1987). Content and formal schemata in ESL reading. TESOL Quarterly, 21, 461-481.

[7] Celce-Murcia, M. (2001). Teaching English as a Second Foreign Language. 3rd ed. New York: Heinle and Heinle Pblishers, a division of Thomson Learning, Inc.

[8] Chang, Y. (2007). The cross-cultural background knowledge in the EFL reading comprehension. Unpublished manuscript, Chia-Nan University of Pharmacy and Science, at Taiwan.

[9] Chastain, K. (2002). Developing Second Language Skills (3rd ed). San Diego: Harcourt Brace Jovanovich, Inc.

[10] Chen, C. (2008). The effect of background knowledge and previews on elementary native Mandarin-speaking English language learners' reading comprehension. Unpublished doctorial dissertation. Florida State University.

[11] Dehghan, F. \& Sadighi, F. (2011). On the cultural schema and Iranian EFL learners' reading performance: a case of local and global items. Pan-Pacific Association of Applied Linguistics, 15 (2), 97-108.

[12] Demir, Y. (2012). The effect of background knowledge and cultural nativization on reading comprehension and vocabulary inference. Journal of Educational and Instructional studies, 2(4), 188-198.

[13] Dornyei, Z. (2011). Research Methods in Applied Linguistics.10rd ed. New York: Oxford University Press.

[14] Driscoll, Liz. (2004). Reading Extra: A resource book of multi-level skills activities. United Kingdom: Cambridge University Press. 
[15] Farhady, H. (2005). Techniques for Effective Reading. Tehran: Rahnama Press.

[16] Fowler, W. \& Coe, N. (1976). Nelson English Language Tests. Australia: Bulter and Tanner Ltd.

[17] Erten, I.H., \& Razi, S. (2009). The effects of cultural familiarity on reading comprehension. Reading in a Foreign Language, $21(1), 66-77$

[18] Ghaniabadi, S., \& Alavi, N. (2012). The impact of teaching culture on reading comprehension and vocabulary knowledge in Iranian EFL learners. Unpublished masters' thesis, Hakim Sabzevari University, Sabzevar, Iran.

[19] Ghazanfari, M., \& Foroughi, F. (2010). The effect of schema activation and schema-theory-based pre-reading activities on enhancing EFL readers' comprehension. Unpublished masters' thesis, Hakim Sabzevari University, Sabzevar, Iran.

[20] Gurkan, S. (2012). The effects of cultural familiarity and reading activities on L2 reading comprehension. Social and Behavioral Sciences, 55, 1196-1206.

[21] Hadson, G. (2002). Essential Introductory Linguistics. Michigan: Blackwell Publishers, Inc.

[22] Harmer, J. (2007). How to teach English. England: Pearson Education Limited.

[23] Hartman, P., \& Mentel,, J. (2002). Interaction Access Reading/Writing. 4th ed. New York: McGraw-Hill Contemporary.

[24] Hills, M.D. (2002). Kluckhohn and Strodtbeck's Values Orientation Theory. International Association for Cross-Cultural Psychology, 8 (1), 1-14.

[25] Hill, Y.Z., \& Lin, O.L. (2012). Is there any interaction between background knowledge and language proficiency that affects TOEFL iBT reading performance? TOEFL iBT Research Report, 12 (22), 1-42.

[26] Hofstede, G. (1980). Culture Consequences. International Differences in Work-Related Values. London: Sage Publications.

[27] Huang, Q. (2009). Background knowledge and reading teaching. Asian Social Science. 5 (5), 138-1542.

[28] Kouhi, D. \& Hosseini Asl, M. (2013). The effect of awareness raising activities on students' reading comprehension: the case of culturally-bound materials. The National Conference of Language, Literature and Translation, Shiraz.

[29] Kramsch, C. (1998). Language and Culture. New York: Oxford university press.

[30] Littlemore, J. (2003). The effect of cultural background on metaphor interpretation. Metaphor and Symbol, 18 (4), $273-288$.

[31] Lin, W. (2013). A study on cross-cultural barriers in reading of English. Unpublished manuscript, English Department of Foshan university of China.

[32] Lin, Z. (2002). Discovering EFL learners' perception of prior knowledge and its roles in reading comprehension. Journal of research in Reading, 25 (2), 172-190.

[33] Mackey, A. \& M.Gass, S. (2005). Second Language Research. New Jersey: Lawrence Erlbaum Associates.

[34] Markstein, L. (1994). Developing Reading Skills. 2nd ed. New York: Heinle and Heinle Pblishers, a division of Thomson Learning, Inc.

[35] Meshkat, M. (2009). Academic Writing: A Practical Guide for Graduate Students. Tehran: Shahid Rajaee Teacher Training University Press.

[36] Nejati, R. \& Ashrafi, H.R. (2010). Statisticts Made Simple (SPSS19). Tehran: Shahid Rajaee Teaching Training University.

[37] Nguen, T. (2012). The impact of background knowledge and the constraint on reading comprehension of Vietnamese learners of English as a second language. Unpublished masters' thesis, Southern Illinois University, Carbondale.

[38] Pallant, J. (2013). SPSS Survival Manual: A step by step guide to data analysis using IBM SPSS. 5th ed. New York: Mc Graw Hill. S

[39] Pollap, T. (2010). The relationship between American cultural background knowledge and the English proficiency of Thai students majoring in English. Unpublished masters' thesis, at Srinakharinwirot University.

[40] Pulido, D. (2004). The effect of cultural familiarity on incidental vocabulary acquisition through reading. The Reading Matrix, 4 (2), 20-53.

[41] Rajabi, P. (2009). Cultural orientation and reading comprehension models: the case of Iranian rural and urban studies. NovitasROYAL, 3(1), 75-82.

[42] Richards, J., \& Schmidt, R. (2002). Longman Dictionary of Language Teaching and Applied Linguistics. 3rd ed. London: Pearson Education limited.

[43] Rivers, W.M. (1981). Teaching Foreign-Language Skills (2nd ed). Chicago: University of Chicago Press.

[44] Ruthemsley, M. (2011). The effect of cultural background on comprehension of English tests by second language learners of English. Unpublished masters' thesis, University of Limpopo.

[45] Ryan, S. (2012). Bringing cultural background knowledge to the surface to better understand cross-cultural conflict in specific contexts. Intercultural Communication Studies, 97 (58), 214-235.

[46] Sharafi, F., \& Barati, H. (2010). The effect of Iranian EFL learners' cultural knowledge on their performance on cloze tests. Unpublished manuscript, Azad University of NajafAbad and University of Isfahan.

[47] Shaghasemi, E., \& Heisey, D.R. (2009). The cross-cultural schemata of Iranian-American people toward each other: a qualitative approach. Intercultural Communications Studies, 10 (8), 143-160.

[48] Tavakoli, M., Shirinbakhsh, S., \& Rezazadeh, M. (2013). Effect of cultural adaptation on EFL reading comprehension: the role of narrative notarization and foreign language attitude. World Applied Sciences Journal, 21 (11), 1596-2013.

[49] Wikipedia. (2013). Cultural Schema Theory. Retrieved June, 28, 2012, from www.en.wikipedia.org/wiki/cultural_schema_theory.html

[50] Xiaqin, Z. (2005). Schema theory and reading comprehension. Unpublished manuscript, Shandong Radio and TV University.

[51] Yamasaki, M. (2010). Strategies to compensate for cultural background knowledge deficiency in L2 reading. Unpublished manuscript.

Farhad Ghorbandordinejad is an Assistant Professor in the TEFL Department of Faculty of Humanities at Shahid Rajaee Teacher Training University of Tehran, Iran. 
Zahra Bayat is from Sabzevar in Iran. She received her M.A in TEFL from Shahid Rajaee Teacher Training University of Tehran in 2014. She is teaching English in Department of Education and ELT Institutes in Iran. Her articles have received and presented in TELLSI and CIVILICA. Her current research interests involve: sociology, cultural studies and teaching ELT skills. 